\title{
CORRECTION \\ Correction to: Situating Culturally Embodied Play Ecologies of Preschool Children: Lost in Transition
}

\section{Kristine Jensen de López ${ }^{1}$}

Published online: 1 October 2018

(C) Springer Science+Business Media, LLC, part of Springer Nature 2018

\section{Correction to: Integr Psych Behav https://doi.org/10.1007/s12124-018-9439-5}

The original version of this article unfortunately contained a mistake. The name of "Kristine Jensen de López" was incorrectly tagged. The correct citation for this article's author should be "Jensen de López, K.". 